\title{
Intimacy or utility? Organ donation and the choice between palliation and ventilation
}

Aric Bendorf*1, Ian H Kerridge ${ }^{1,2}$ and Cameron Stewart ${ }^{1,3}$

\begin{abstract}
Organ donation after brain death provides the most important source for deceased organs for transplantation, both because of the number of potential organ donors that it makes available and also because of the unparalleled viability of the organs retrieved. Analysis of worldwide deceased organ donation rates demonstrates that all countries with high deceased organ donation rates (>20 donors per million population per year) have high brain death rates ( $>40$ brain deaths per million population per year). This analysis makes it clear that countries striving to increase their deceased organ donor rates to world leading levels must increase the rates of donation after brain death. For countries with end-of-life care strategies that stress palliation, advance care planning and treatment withdrawal for the terminally ill, the adoption of initiatives to meaningfully raise deceased donor rates will require increasing the rate at which brain death is diagnosed. This poses a difficult, and perhaps intractable, medical, ethical and sociocultural challenge as the changes that would be required to increase rates of brain death would mean conjugating an intimate clinical and cultural focus on the dying patient with the notion of how this person's death might be best managed to be of benefit to others.
\end{abstract}

\section{Introduction}

The way we die has changed significantly during the past half-century. Once a sudden and unexpected event, death has become an actively managed and often prolonged process that occurs more often in hospitals than in the community [1,2]. Advances in biotechnology, biomedicine and critical care, in particular, have transformed the

${ }^{*}$ Correspondence: aric.bendorf@sydney.edu.au

'The Centre for Values, Ethics and the Law in Medicine (VELiM), Level 1, Medical Foundation Building K25, 92-94 Parramatta Road, University of Sydney, Sydney, NSW 2006, Australia

Full list of author information is available at the end of the article way we die [3-5]. Organ failure, for example, is no longer inextricably linked to death. Patients with end-stage renal disease are routinely dialyzed for many years. The lives of patients with cardiac failure can be prolonged with inotropic and chronotropic therapies, and patients with respiratory failure can receive invasive and non-invasive ventilation in hospital or at home. Also, for more than 100,000 patients per year of the estimated 1.7 million patients worldwide in need of transplant for failing organs [6,7], the transplantation of organs and tissues from patients that have died in intensive care settings provide significant benefits - reducing mortality and morbidity, increasing long-term survival, increasing quality of life and reducing the economic burden of the cost of healthcare for patients with chronic diseases [8].

The ICU has therefore come to play multiple important roles in contemporary healthcare - providing access to advanced life support, supporting organ donation and tissue transplantation programs, and providing end-oflife care for those in whom any further treatment is futile [9]. While these functions are generally managed without difficulty, they may, at times, create an unavoidable tension, particularly when intensivists must mediate between professional and social obligations to provide patients with a good death $[10,11]$, to effectively use scarce health resources and to support organ transplantation through the identification and management of people who are, or may become, brain dead.

Brain death is the most important method for procuring deceased organs for transplantation, both because of the number of potential organ donors that it makes available and also because of the unparalleled viability of the organs retrieved [12]. But this method, in itself, creates a unique challenge because, where brain death is anticipated, the interests of the patient, and the public benefit that accrues from the organs potentially removed from that patient may diverge, creating tension regarding the most appropriate approach to the management of the patient's death. The successful management of this tension may be the major determinant of the degree to which a country is able to meet its organ donation requirements. The ICU has therefore become the place in which both medicine and society confront a choice 


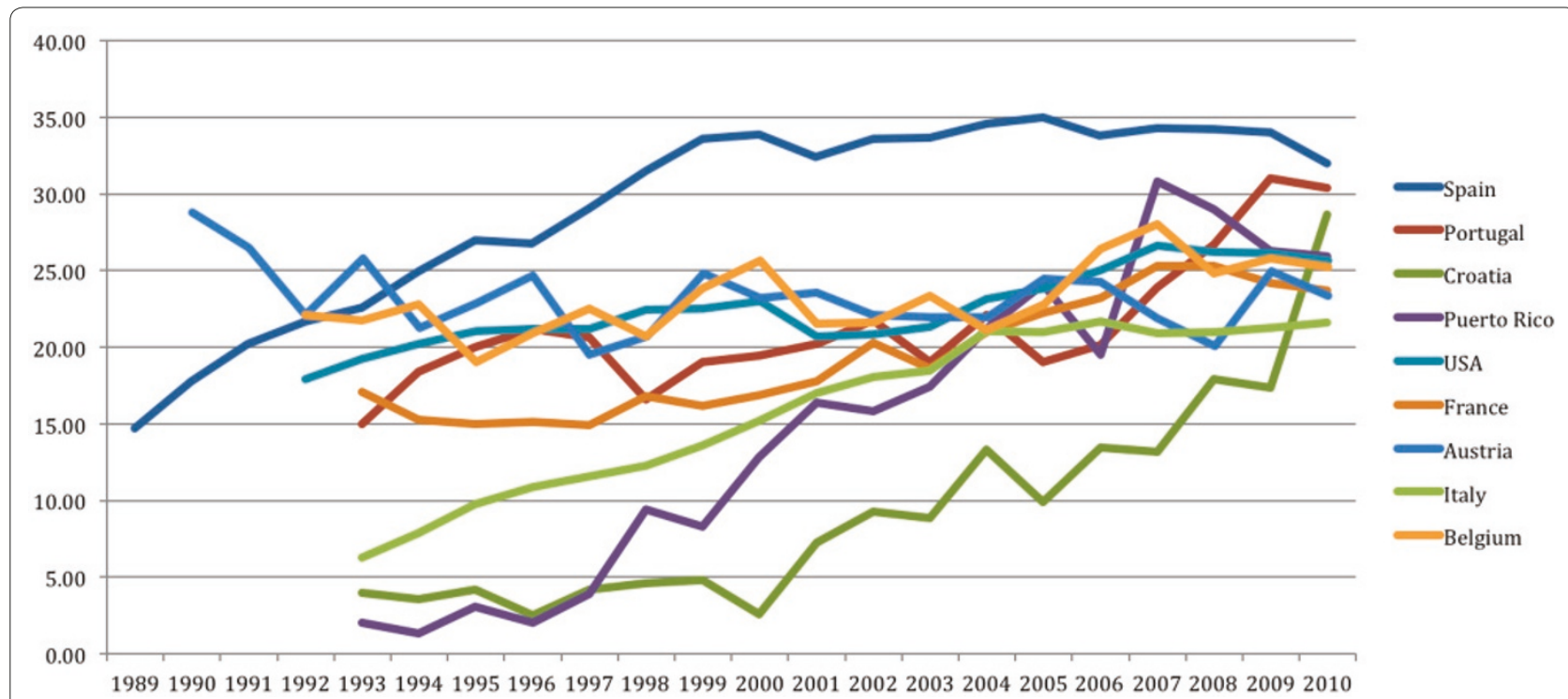

Figure 1. Deceased donation rates for countries achieving $>\mathbf{2 0}$ donors per million population per year 1989-2010. Graph demonstrating the general trend toward consistently increasing deceased organ donor rates over time in the countries with the world's highest deceased organ donor rates. This illustrates that decreasing trauma rates have not adversely affected rates of organ donation in these countries. Data from [6,15].

between increasing organ donation and the provision of a less invasive approach to end-of-life care, where we, collectively, balance the intimacy of a good death and the utility of increased donation rates, through provision of intensive care until brain death occurs.

\section{Relationship between organ donation and brain death}

Recent multi-year analyses of deceased donor data from both the Council of Europe and the International Registry of Donation and Transplants have shown that there is a clear division in deceased organ donation performance between those countries that have the highest donation rates and those with lower deceased donation performance [13-15]. This division occurs at approximately 20 deceased donors per million population per year. There are nine countries that consistently achieve donation rates above this level despite having dramatically reduced death rates from the types of rates of trauma that are most commonly associated with organ donation [13]: Spain, Portugal, Puerto Rico, Croatia, the USA, France, Austria, Belgium and Italy (Figure 1). Crucially, each of these countries' high donor rates is due to the high rates of donation after brain death (DBD) and not due to the high rates of donation after cardiocirculatory death (DCD) [16-22] (Figure 2).

While DCD plays an increasingly central role in the organ donor policies in many countries and has contributed to raising organ donation rates in Spain, France, Belgium, the USA, the UK and Australia, DCD strategies are not unproblematic. Although DCD organ recovery and graft survival rates for kidneys and lungs now approach those of DBD donors in many countries [23,24], recovery rates for other DCD organs - especially livers remain less than those following DBD [25]. Recovery rates following DCD are also approximately 1.5 times lower, per donor, than DBD and there are some data to suggest that increased DCD donation may come at the expense of reducing DBD donation [26,27]. An international comparison of deceased donation rates demonstrates clearly that the high DBD rates observed in the leading donor countries are directly associated with high rates of brain death (>40 per million population) [28] (Figure 3).

There are many factors that determine whether a person becomes an organ donor and, consequently, many reasons why the deceased organ donor pool may be diminished. Reductions in the rates of traumatic brain injury - specifically, traffic and stroke fatalities together with advances in emergency and critical care - have reduced the numbers of patients reaching brain death criteria and therefore reduced the number of potential organ donors [13,29-31]. Also, while not directly affecting the rates of brain death, the aging of the population and increases in the rates of noncommunicable diseases (that is, diabetes) may serve to reduce the number of organs suitable for transplant. While both upstream and downstream factors - such as consent rates, donor optimization, improved organ preservation, and more rigorous recipient selection - may positively impact upon organ donor rates and transplantation outcomes, the relationship between any of these factors and donation and transplantation outcomes is not straightforward. The impact of end-of-life care and decision-making on rates of brain death and organ donation is even less clear. 


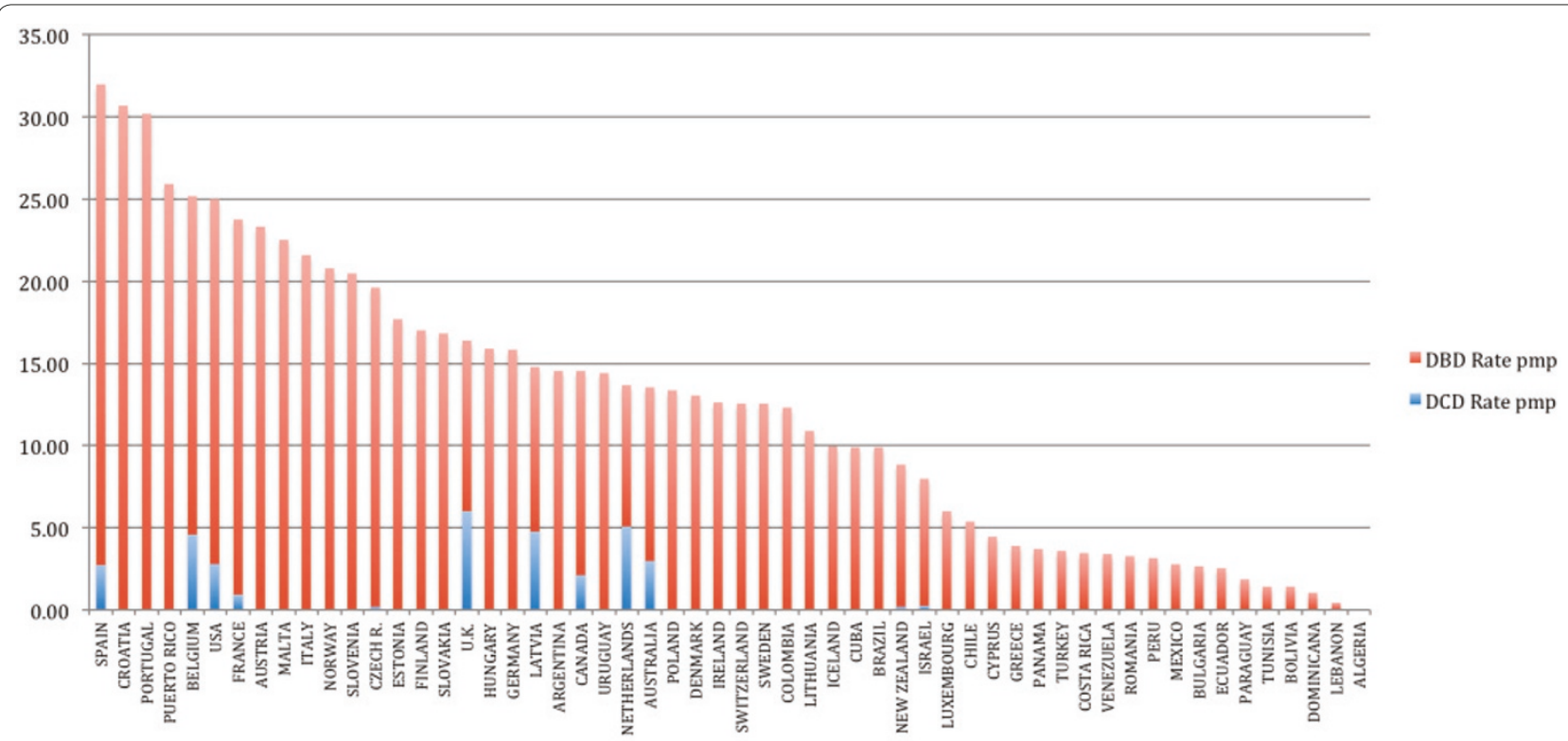

Figure 2. Deceased donation rates per million population by donation after brain death and cardiocirculatory death, 2010. Graphic demonstrating the strong predominance of contribution from donation after brain death (DBD) and minimal donation after cardiocirculatory death (DCD) to deceased organ donation rates of countries with the highest donation rates. pmp, per million population. Data from $[6,15]$.

While there is some literature dealing with end-of-life practices in ICU settings [32-34], there is much less literature that makes explicit the tension between palliative care and organ donation and it remains unclear why there are such significant differences in rates of brain death in developed countries when the factors that lead to brain death are likely to be broadly equivalent in these countries and other metrics that one may expect to be salient, such as the number of ICU beds per capita, appear to have little influence on brain death rates or organ donation rates [35]. One possibility is that the high rates of brain death observed in all countries that have high deceased donor rates may be related to more aggressive interventional approaches to end-of-life care that are part of these countries' standard treatment protocols in intensive care [36-38]. Conversely, developed countries with lower rates of brain death - such as Australia, where brain death is normally only formally diagnosed when the potential donor's family has agreed to donation [39] - may approach end-of-life care less aggressively, may stress treatment withdrawal and palliation for cases in which treatment is deemed to be futile, may be less likely to emphasize the value of intensive care admission and cardiorespiratory support, and may be less likely to seek a diagnosis of brain death.

\section{Cultural and religious factors affecting death management}

Different approaches to end-of-life care and different social conventions regarding what is and what is not appropriate or acceptable during life's final moments are likely to reflect cultural values, religious beliefs, legal norms and medical practices. Collectively, these may determine the extent to which technology is integrated into death's approach and arrival, the specific point at which society considers a person to be well and truly dead, and the use of heroic measures, including intensive care. These approaches to end-of-life care are critically important with regard to the success of organ donation and transplantation programs because they will determine when and how frequently brain death is used as the criterion by which death is declared. In cultural settings where aggressive intensive care is not the norm, patients are less likely to progress through to a diagnosis of brain death. Where faith traditions privilege bodily integrity, cosmological integration, rapid burial, or prolonged rituals of grieving (as may be the case with both eastern and Abrahamic faith traditions), there may be less support for the application of biotechnology at the end of life and for organ donation.

A number of factors may mitigate against the application of intensive and invasive technology during endof-life care (and therefore the diagnosis of brain death), including: Do Not Resuscitate orders and advance care planning that limits the provision of invasive treatment; professional reluctance to provide futile care; policies that restrict admission of futile cases into intensive care; availability of ICU resources; increased social and political support for palliative care and services that enable death in community settings; sociocultural attitudes against the 


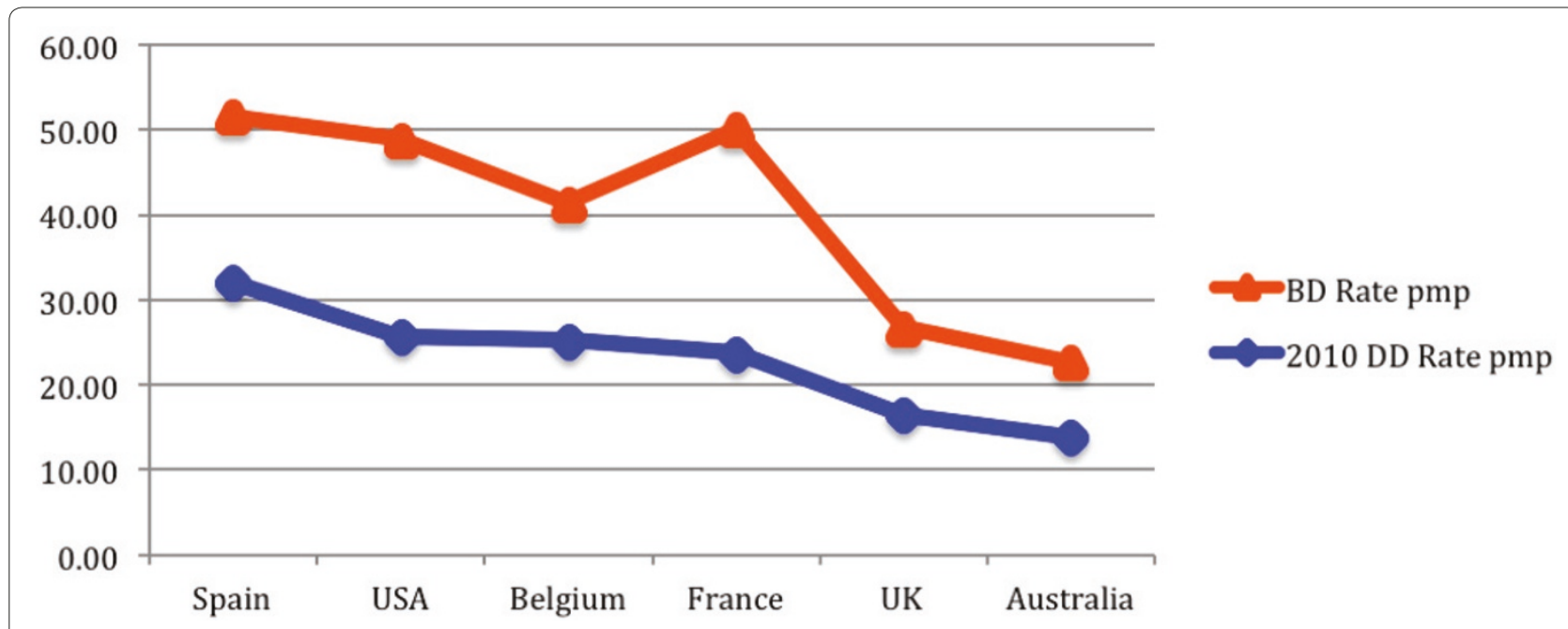

Figure 3. Brain death rates and 2010 deceased donation rates. Brain death (BD) rates and 2010 deceased donation (DD) rates of countries with published national rates of BD. Graphic demonstrating a high degree of correlation between countries with high (>40 per million population $(\mathrm{pmp})$ ) rates of $\mathrm{BD}$ and high (>20 pmp) DD rates. The lower DD rates for the UK and Australia correlate with their lower BD rates. Data for DD from [6]. Data for BD from [16] for Spain, [20] for France, [44] for USA midpoint, [38] for Belgium, [45] for the UK, and [46] for Australia.

application of invasive technologies at the end of life; and increasing public and professional emphasis on ensuring that people with terminal illness have a good death.

\section{A difficult choice: intimacy versus utility}

To increase rates of organ donation in countries which privilege advance care planning and treatment withdrawal over aggressive treatment in intensive care particularly in patients with severe brain injury - policymakers and health professionals confront a difficult choice. The measures necessary to increase rates of brain death, and thereby the availability of transplantable organs, would require fundamental changes in clinical care at the end of life - changes that may appear inconsistent with accepted norms surrounding what constitutes appropriate care at the end of life and the appropriate management of a good death.

One option available to countries with low deceased donation rates is to try to raise rates of brain death by redefining what is considered appropriate treatment in end-of-life care - specifically, to normalize the widespread application of technology at the end of life and to continue cardiorespiratory support in patients who currently have treatment withdrawn as part of the active management of their dying [40]. The impact of such a move (as has been recently proposed in the UK $[41,42]$ ) would be profound - increasing expenditure at the end of life, increasing ICU admission rates and the number of ICU beds required, privileging intensive care over palliative and chronic care, readjusting our expectation of advance care planning to accommodate interventions that maximize organ donation potential, adjustment of public health policies to encourage hospital-based and intensive care, and changing social attitudes and expectations regarding where and how we should die. Each of these strategies requires fundamental changes to our attitudes and expectations regarding the way in which we die. Each would also represent a major policy reversal from efforts in most common law countries, which in recent decades have generally rejected moves toward presumed consent legislation and have aimed to decrease levels of unwanted end-of-life interventions and to increase the effectiveness of advance care planning for treatment limitation [43].

The other option is to accept lower brain death rates and constrained numbers of deceased organ donors as a consequence of maintaining approaches that limit endof-life interventions and futile care and that encourage advance care planning, treatment limitation and dying in community and hospice settings.

One of these options is concerned primarily with the best interest of the dying patient while the other sacrifices some degree of intimacy in dying for the social utility of organs and tissues. Moreover, it conjugates a previously singular sanctity of focus on a peaceful, minimally intrusive pathway to death for a more aggressive and mechanical approach that views a patient's death not just as an unfortunate tragedy but also as a potential utility to helping others.

Clearly it is important to continue research into strategies that may increase the recruitment of organ donors and raise rates of consent for donation, into methods for optimizing organ and patient outcomes following DCD, and into the emergent sciences that may ultimately 
reduce our reliance upon organ donation. At this point, however, the evidence is clear - only through increasing the diagnosis of brain death can countries realize the numbers of deceased organ donors needed to best meet the demand for organs for transplantation. We believe it is time to put aside the idea that we can significantly increase deceased organ donation rates without significantly increasing brain death rates. Doing so will enable the public and professional debate to move to where we believe it should be - a discussion about what we are prepared to do and what we are prepared to give up, in order to expand our transplantation programs.

\section{Abbreviations}

$\mathrm{DBD}$, donation after brain death; $\mathrm{DCD}$, donation after cardiocirculatory death.

\section{Competing interests}

The authors declare that they have no competing interests.

\section{Author details}

'The Centre for Values, Ethics and the Law in Medicine (VELiM), Level 1, Medical Foundation Building K25, 92-94 Parramatta Road, University of Sydney, Sydney, NSW 2006, Australia. ${ }^{2}$ Haematology Department, Royal North Shore Hospital, Pacific Highway, St Leonards, NSW 2065, Australia. ${ }^{3}$ The Centre for Health Governance, Law and Ethics, Sydney Law School, Building F10, Eastern Ave, University of Sydney, Sydney, NSW 2006, Australia.

\section{Published: 23 May 2013}

\section{References}

1. Higginson IJ, Astin P, Dolan S: Where do cancer patients die? Ten-year trends in the place of death of cancer patients in England. Palliat Med 1999, 12:353-363.

2. Flory J, Young-Xu Y, Gurol I, Levinsky N, Ash A, Emanuel E: Place of death: US trends since 1980. Health Affairs 2004, 23:194-200.

3. Diagnosis of Death. Memorandum issued by the honorary secretary of the Conference of Medical Royal Colleges and their Faculties in the United Kingdom on 15 January, 1979. Br Med J 1979, 1:332.

4. Ariès P: Western Attitudes Toward Death. Translated by Ranum PM. Baltimore, MD: The Johns Hopkins University Press; 1974.

5. Machado C: A new definition of death based on the basic mechanisms of consciousness generation in human beings. In Brain Death - Proceedings of the Second International Symposium on Brain Death. Edited by Machado C. Amsterdam: Elsevier Science; 1995:57-66.

6. Council of Europe: International figures on donation and transplantation 2010. Newslett Transp/2011, 16:25. [http://www.ont.es/publicaciones/ Documents/Forms/Alltems.aspx]

7. Schieppati A, Remuzzi G: Chronic renal diseases as a public health problem: epidemiology, social, and economic implications. Kidney Int Supp/ 2005, 98:S7-S10.

8. Mendeloff J, Ko K, Roberts MS, Byrne M, Dew MA: Procuring organ donors as a health investment: how much should we be willing to spend? Transplantation 2004, 78:1704-1710.

9. Smith II GP: Law and Bioethics: Intersections Along the Mortal Coil. New York: Routledge; 2012.

10. Kehl K: Moving toward peace: an analysis of a good death. Am J Hosp Palliat Care 2006, 23:277-286.

11. Walter T: Historical and cultural variants on the good death. BMJ 2003, 187:218-220.

12. Beecher HK: A definition of irreversible coma. Report of the ad hoc committee of the Harvard Medical School to examine the definition of brain death. JAMA 1968, 205:337-340

13. Bendorf A, Kerridge $\|_{H}$, Kelly PJ, Pussell B, Guasch X: Explaining failure through success: a critical analysis of reduction in road and stroke deaths as an explanation for Australia's low deceased organ donation rates. Internal Med J 2012, 42:866-873.

14. Council of Europe: International figures on donation and transplantation 2005 thru 2010. Newslett Transp/ 2006-2011, 11-16. [http://www.ont.es/publicaciones/Documents/Forms/Alltems]
15. International Registry of Donation and Transplantation Deceased Donors Database [www.tpm.org.es]

16. Organización Nacional de Trasplantes: Programa de Garantía de Calidad del Processo de Donación. Evolutivo de Resultados de la AutoEvaluación 1998-2009. Madrid: Organización Nacional de Trasplantes; 2010.

17. Colheita e Transplantação de Órgãos e Tecidos: Relatório Estatístico 2009. Lisbon: Autoridade para os Serviços de Sangue e da Transplantação; 2010.

18. Busic M, Lovrencic-Huzjan A: Action taken to boost donor rate in Croatia. In Organ Donation and Transplantation - Public Policy and Clinical Perspectives. Edited by Randhawa G; Rijeka, Croatia: InTech; 2012. [http://www.intechopen.com/books/ organ-donation-and-transplantation-public-policy-and-clinical-perspectives]

19. Organ Procurement and Transplantation Network: Deceased Donors Recovered in the US by Mechanism of Death; and, Deceased Donors Recovered in the US by Circumstance of Death. Washington, DC: US Department of Health and Human Services; 2010. [http://optn.transplant.hrsa.gov/latestData/step2.asp]

20. Agence de la Biomédecine: Rapport annuel 2010. Activités: données essentielles. Paris: Agence de la Biomédecine; 2011

21. Eurotransplant International Foundation: Annual Report (2005-2011). Edited by Oosterlee A, Rahmel A. Leiden: Eurotransplant International Foundation; 20062012. [http://www.eurotransplant.org/cms/index.php?page=annual_reports]

22. Centro Nazionale Trapianti, Istituto Superiore di Sanità: Valutazione di qualità dell'attività del trapianto 2000-2009. Rome: Rete Nazionale Trapianti, Centro Nazionale Trapianti, Istituto Superiore di Sanità; 2011. [http://www.salute.gov. it/cnt/cntDettaglioMenu.jsp?id=73\&area=cnt-organi\&menu=menuPrincipale \&sotmenu=qualita\&label=moq\&livello=1]

23. Bellingham JM, Santhanakrishan C, Meidlinger N, Wai P, Kim J, Niederhaus S, Leverson GE, Fernandez LA, Foley DP, Mezrich JD, Odorico JS, Love RB, De Oliveira N, Sollinger HW, D'Alessandro AM: Donation after cardiac death: a 29-year experience. Surgery 2011, 150:692-702.

24. Zych B, Propov AF, Armani M, Bahrami T, Redmond KC, Krueger H, Carby M, Simon AR: Lungs from donation after circulatory death donors: an alternative source to brain-dead donors? Midterm results at a single institution. Eur J Cardiothorac Surg 2012, 42:542-549.

25. Orman ES, Barritt AS, Wheeler SB, Hayashi PH: Declining liver utilization for liver transplantation in the United States and the impact of donation after cardiac death. Liver Transp/ 2013, 19:59-68.

26. Dominguez-Gil B, Haase-Kromwijk B, Van Leiden H, Neuberger J, Coene L, Morel P, Corinne A, Muehlbacher F, Brezovsky P, Costa AN, Rozental R, Matesanz R; European Committee (Partial Agreement) on Organ Transplantation. Council of Europe: Current situation of donation after circulatory death in European countries. Transpl Int 2011, 24:676-686.

27. Nath J, Mellor SJ: Organ transplantation after cardiac death (response). Lancet 2011, 377:203.

28. Bendorf A, Kerridge IH, McCaughan GW, Myerson B, Stewart C, Pussell BA: An international comparison of the effect of policy shifts to organ donation following cardio-circulatory death (DCD) on donation rates after brain death (DBD) and transplantation rates. In 24th International Congress of the Transplantation Society. 16 July 2012. Berlin: The Transplantation Society. [http://www.tts.org/index.php?option=com_tts\&view=presentation\&id=12257]

29. Maegele M, Engel D, Bouillon B, Lefering R, Fach H, Raum M, Buchheister B, Schaefer U, Klug N, Neugebauer E: Incidence and outcome of traumatic brain injury in urban area in Western Europe over 10 years. Eur Surg Res 2007, 39:372-379.

30. Pérez K, Novoa AM, Santamariña-Rubio E, Narvaez Y, Arrufat V, Borrell C, Cabeza E, Cirera E, Ferrando J, García-Altés A, Gonzalez-Luque JC, Lizarbe V, Martin-Cantera C, Seguí-Gómez M, Suelves JM; Working Group for Study of Injuries of Spanish Society of Epidemiology: Incidence trends of traumatic spinal cord injury and traumatic brain injury in Spain, 2000-2009. Accid Anal Prev 2012, 46:37-44.

31. Andelic N, Anke A, Skandsen T, Sigurdardottir S, Sandhaug M, Ader T, Roe C: Incidence of hospital-admitted severe traumatic brain injury and inhospital fatality in Norway: a national cohort study. Neuroepidemiology 2012, 38:259-267.

32. Sprung $C L$, Sjokvist P, Baras M, Bulow HH, Hovilehto S, Ledoux D, Lippert A, Maia P, Phelan D, Schobersberger W, Wennberg E, Woodcock T; Ethicus Study Group: End-of-life practices in European intensive care units: the Ethicus Study. JAMA 2003, 290:790-797.

33. Sprung CL, Maia P, Bulow HH, Ricou B, Armaganidis A, Baras M, Wennberg E, Reinhart K, Cohen SL, Fries DR, Nakos G, Thijs LG; Ethicus Study Group: The importance of religious affiliation and culture on end-of-life decisions in 
European intensive care units. Intensive Care Med 2007, 33:1732-1739.

34. Devictor DJ, Nguyen DT: Forgoing life-sustaining treatments in children: a comparison between Northern and Southern European pediatric intensive care units. Pediatr Crit Care Med 2004, 5:211-215.

35. Adhikari NKJ, Fowler RA, Bhagwanjee S, Rubenfeld GD: Critical care and the global burden of critical illness in adults. Lancet 2010, 376:1339-1346.

36. Feest TG, Riad HN, Collins CH, Golby MG, Nicholls AJ, Hamad SN: Protocol for increasing organ donation after cerebrovascular deaths in a district general hospital. Lancet 1990, 335:1133-1135.

37. Ball C, Navsaria P, Kirkpatrick AW, Vercler C, Dixon E, Zink J, Laupland KB, Lowe M, Salomone JP, Dente CJ, Wyrzykowski AD, Hameed SM, Widder S, Inaba K, Ball JE, Rozycki GS, Montgomery SP, Hayward T, Feliciano DV: The impact of country and culture on end-of-life care for injured patients: results from an international survey. J Trauma 2010, 69:1323-1333; discussion 1333-1334.

38. Van Gelder F, Van Hees D, De Roey J, Desschans, B, Monbaliu D, Coosemans W, Aerts R, Van Raemdonck D, Pirenne J: In hospital retrospective death record registration and review confirms therapy discontinuation as a major cause of under detection of potential donors. Transpl Int 2007 20(Suppl 2):37.

39. Kerridge $I H$, Saul P, Lowe M, McPhee J, Williams D: Death, dying and donation: organ transplantation and the diagnosis of death. J Med Ethics 2002, 28:89-94.

40. Matesanz R, Coll E, Domiguez-Gil B, de la Rosa G, Marazuela R, Arráez V, Elorrieta P, Fernández-Renedo C, Galán J, Gómez-Marinero P, MartínDelagebasala C, Martín-Jiménez S, Masnou N, Salmero P, Sánchez-lbánez J, Serna E, Martínez-Soba F, Pastor-Rodríguez A, Bouzas E, Castro P:
Benchmarking in the process of donation after brain death: a metholodology to identify best performer hospitals. Am J Transp/ 2012, 13:2498-2506.

41. Monette M: British docs urge elective ventilation. Can Med Assoc J 2010. [http://www.cmaj.ca/content/early/2012/10/09/cmaj.109-4259.full.pdf+html]

42. British Medical Association: Building on Progress: Where Next for Organ Donation Policy in the UK? London: British Medical Association; 2012. [http:// bma.org.uk/working-for-change/improving-and-protecting-health/ organ-donation]

43. Stewart CL: Law and cancer at the end of life: the problem of nomoigenic harms and the five desiderata of death law. Public Health 2011. 125:905-918.

44. Sheehy E, Conrad SL, Brigham LE, Luskin R, Weber P, Eakin M, Schkade L, Hunsicker L: Estimating the number of potential organ donors in the United States. N Engl J Med 2003, 349:667-674.

45. National Health Service: Potential Donor Audit Summary: Report for the 12 Month Period 1 April 2010-31 March 2011. London: National Health Service; 2011.

46. DonateLife Australia: Performance Report 2011. Canberra: Organ and Tissue Authority, Department of Health and Ageing; 2012.

doi:10.1186/cc12553

Cite this article as: Bendorf $A$, et al.: Intimacy or utility? Organ donation and the choice between palliation and ventilation. Critical Care 2013, 17:316 
50.00

40.00

30.00

20.00

10.00

0.00

Figure 3

Spain

USA

Belgium France

UK

Australia

BD Rate pmp

2010 DD Rate pmp 